\section{Total Anomalous Pulmonary Venous \\ Connection - Least Common Type Delineated on Computed Tomography -}

Fumiya Yoneyama, MD; Toru Okamura, MD, PhD

$\mathbf{T}$ he mixed type of total anomalous pulmonary venous connection (TAPVC) is a rare variant occurring in $5-7 \%$ of all patients. ${ }^{1}$ Specifically, "dual" or "double" drainage via a common venous confluence (i.e., a common venous confluence connected to 2 anomalous sites) is even rarer. ${ }^{2}$ A patient who underwent TAPVC repair had unobstructed drainage of all 4 pulmonary veins to both left vertical vein and coronary sinus (Figure). In these cases, when the anatomy does not fit the Darling classification, precise, preoperative evaluation using computed tomography along with echocardiography ${ }^{3}$ is effective to confirm the pulmonary venous anatomy in TAPVC.

\section{Disclosures}

The authors declare no conflicts of interest.

\section{References}

1. Seale AN, Uemura H, Webber SA, Partridge J, Roughton M. Total anomalous pulmonary venous connection: Morphology and outcome from an international population-based study. Circulation 2010; 122: 2718-2726.

2. Imoto Y, Kado H, Asou T, Shiokawa Y, Tominaga R, Yasui H. Mixed type of total anomalous pulmonary venous connection. Ann Thorac Surg 1998; 66: 1394-1397.

3. Jiang L, Xie LJ, Yang ZG, Shi K, Xu HY, Li R, et al. Preoperative evaluation of anomalous pulmonary venous connection using dual-source computed tomography: Comparison with echocardiography. Eur J Radiol 2017; 94: 107-114.

Received July 23, 2018; accepted August 1, 2018; J-STAGE Advance Publication released online September 7, 2018 Time for primary review: 9 days

Department of Cardiovascular Surgery, Nagano Children's Hospital, Azumino, Japan

Mailing address: Fumiya Yoneyama, MD, Department of Cardiovascular Surgery, Nagano Children's Hospital, 3100 Toyoshina, Azumino 399-8288, Japan. E-mail: fumiya.y@hotmail.co.jp

ISSN-1346-9843 All rights are reserved to the Japanese Circulation Society. For permissions, please e-mail: cj@j-circ.or.jp

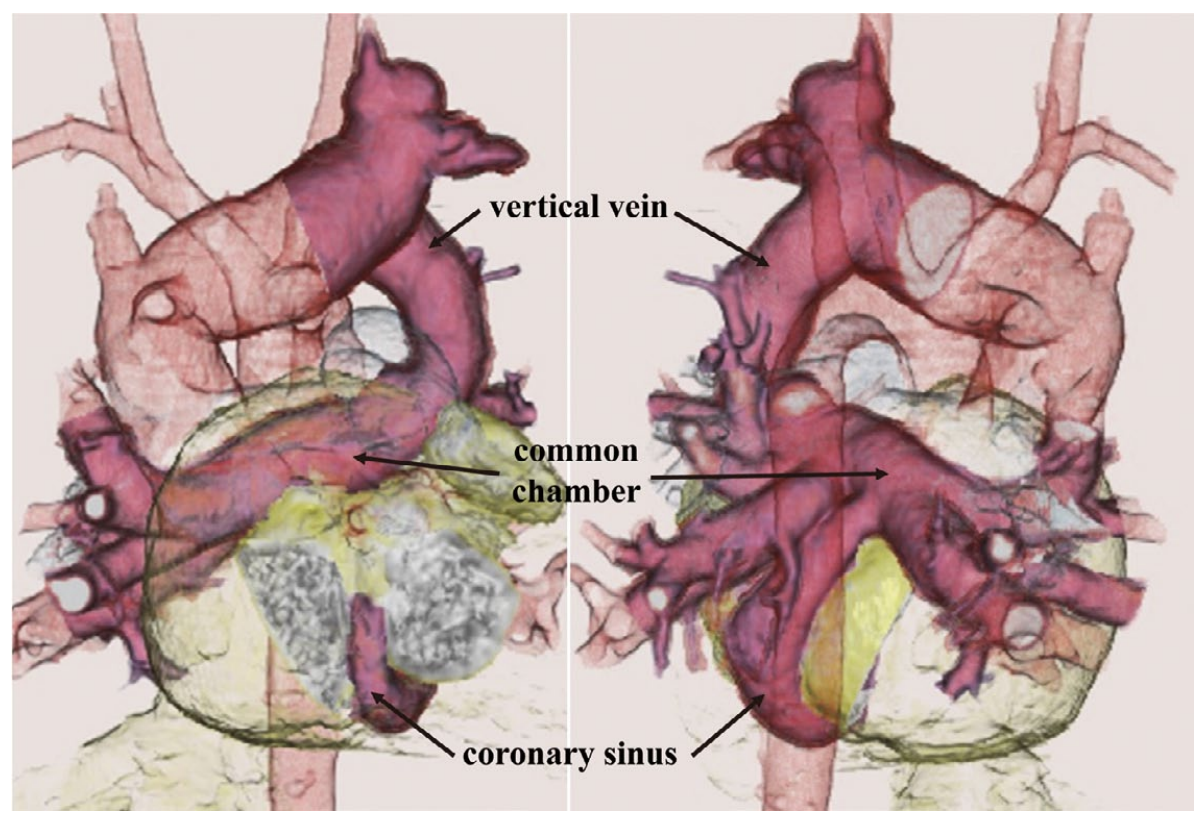

Figure. 